\title{
Tumor Pain, CTCAE 5.0
}

National Cancer Institute

\section{Source}

National Cancer Institute. Tumor Pain, CT CAE 5.0. NCI Thesaurus. Code C146782.

A disorder characterized by a sensation of marked discomfort from a neoplasm that

may be pressing on a nerve, blocking blood vessels, inflamed or fractured from metastasis. 